\title{
Railway Route Crack Detection System
}

\author{
Laxmi Goswami
}

\begin{abstract}
This paper proposes a railway route crack detection system. More particularly, this paper presents the detection system that is capable of detecting any cracks or disjoints in the railway tracks by using microcontroller based smart robot. Most of the goods are transferred from one region to another region through railways only due to its low transportation cost, fastness, reliability and less chance of accident. For long distance travel, lots of people prefer railways rather then roadways as trains are very much comfort and fare are also very less. Therefore, for these reasons it is very necessary to provide a safety to the tracks of railways. Hence for this an advance technology-based robot is develop that is capable of locating faults or cracks in the tracks and protect the trains from any accident.
\end{abstract}

Keywords- Railways crack, microcontroller, smart robot, crack detection.

\section{INTRODUCTION}

In present era, roadways and railways are important part of human beings because without these transportations it is impossible to travel for a long distance. Among all, railways are best source of transportation due to its low cost, easily available and most reliable. Many different types of goods and products are also shipped through railways [1],[2]. In India, most of the people prefer trains for travelling rather than car busses or any other roadways because the road contains large number of holes due to which jerking take place [3]. And if there is a senior citizen it would be very difficult for them to travel from these types of roads that's why people give more priority to railways for traveling rather than roadways. Thus, it is required to provide proper safety to the user travelling in trains [4],[3]. Since from the past history it is absorbed that most of the accident take place in railways is due to the rail track cracks or disjoints in tracks [5]. These disjoints and cutting in railway tracks causes a serious problem and are major factors that results in rail accident and due to such accident people can loss their life [6],[7]. Hence to prevent rail accident it is very necessary to improve the quality of railway tracks by doing regular inspection. Therefore, this paper proposes an advanced technology-based robot that is capable of doing inspection and detecting any faults or cracks in the railway tracks [8].

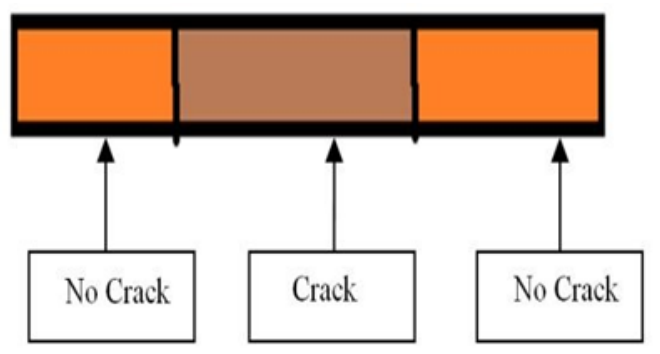

Fig.1 Crack portion in tracks

\section{PROPOSED SYSTEM}

The block diagram of proposed system is shown by figure. 1 the proposed system is based on the wireless technology [9] in which the combination of hardware and software can detect the total number of cracks on the railway tracks. This detection system is installed on the cheches of robot that is going to move on the railway track and detects the number of cracks. The microcontroller is installed in the robot to control the movement of the robot and allows to show number of cracks on the crack.

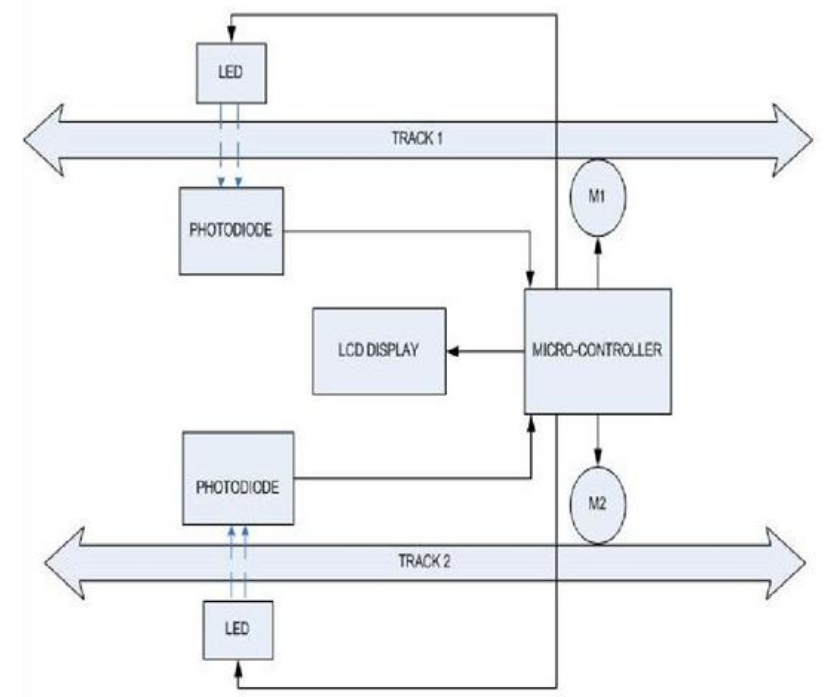

Fig.2 working of proposed system

The LCD display is located on the robot to display the number of counted cracks or disjoints on the railway tracks. The robot is driven through the dc motors [10] that is two in number. Both the dc motor is connected to the tire of robot to give movement to it. The main advantage of such system is that it reduces the human effort by making whole of the system wireless. It is cost effective and less bulky. This robot eliminates the manual operation of detecting cracks as done by the railways previously.

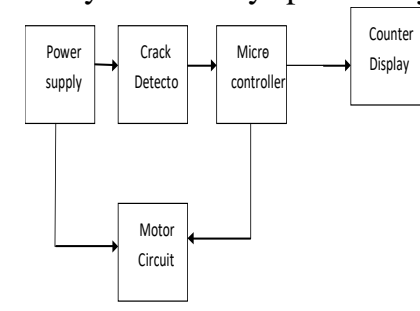

Fig.3 Block Diagram of Proposed System

Revised Manuscript Received on 14 September, 2019.

Laxmi Goswami, Department of Electrical Engineering, Sanskriti University, U.P. India.(Email: sanpubip@ gmail.com) 
From figure. 3 the block diagram of proposed system consists of a power supply unit, crack detection sensor, microcontroller, display unit and a motor controlling driver. The power supply to the robot is given through a $12 \mathrm{v}$ battery attached to it, after providing power to the system the robot is actuated. The sensor detects the cracks while traveling through the robot on the railway track. If it detects any cracks or disjoints, sends the signal to the microcontroller [11] and microcontroller further transmit the detected signal to a LCD displaying unit for showing the number of cracks. The GPS module [12] is also placed inside the system to alert the user by sending the exact location of cracks. The movement of dc motor is controlled by the microcontroller.
Table 1: State diagram

\begin{tabular}{|c|c|c|c|}
\hline INPUT 1 & INPUT 2 & $\begin{array}{c}\text { ENABLE } \\
1,2\end{array}$ & RESULT \\
\hline 0 & 0 & 1 & Stop \\
\hline 0 & 1 & 1 & $\begin{array}{c}\text { Anti- clockwise } \\
\text { rotation }\end{array}$ \\
\hline 1 & 0 & 1 & Clockwise rotation \\
\hline 1 & 1 & 1 & stop \\
\hline
\end{tabular}

Table 1. represents the working of dc motor through controlling the motor driver with the help of microcontroller.

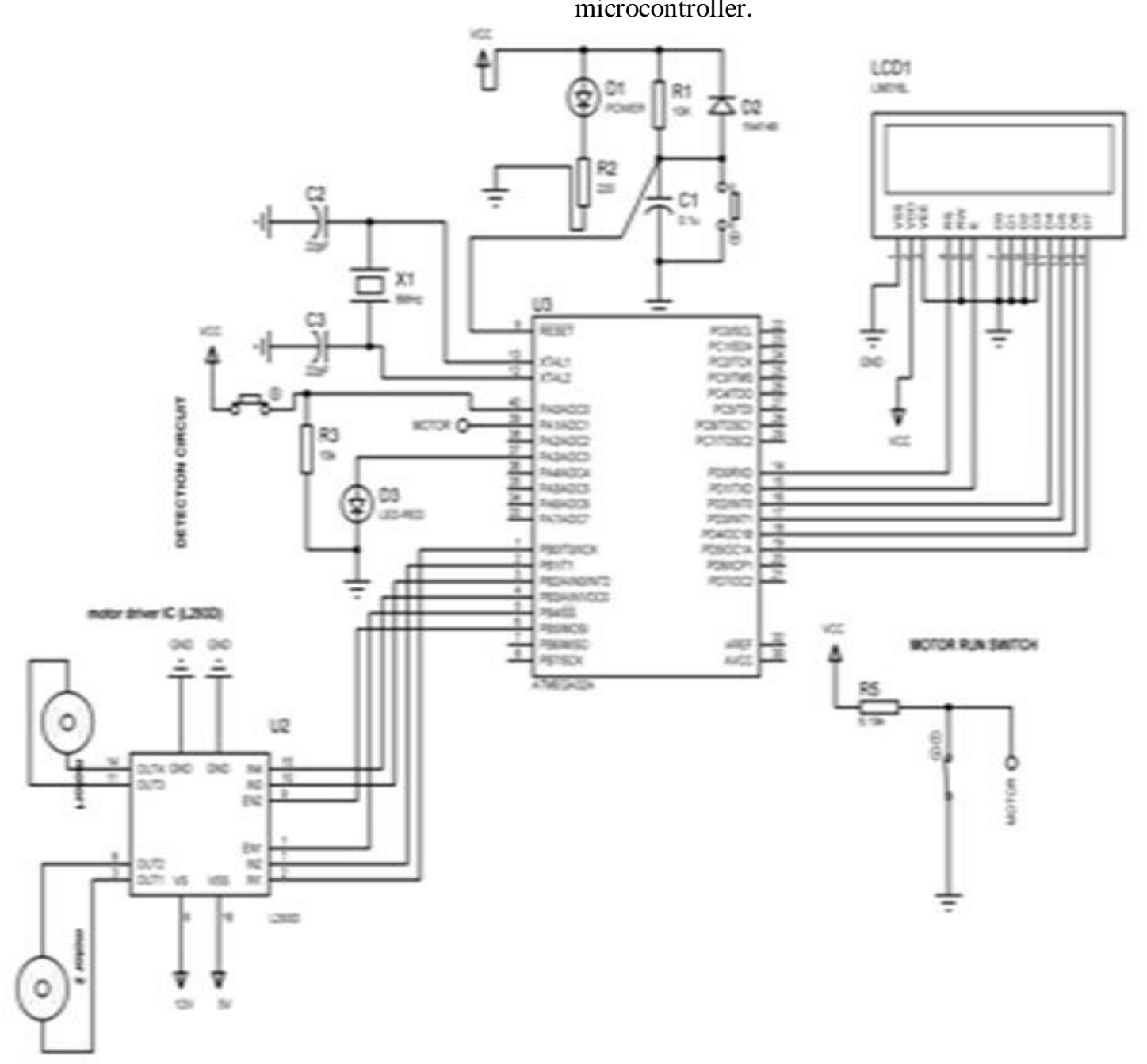

\section{Fig- 4: Circuit diagram of system}

If no input is given then the motor remains in steady state. If only input 2 is given then the robot will move in anticlockwise direction and if input supply is given to input port 1 only then the robot will move in forward direction and both inputs is given then motor will stop.

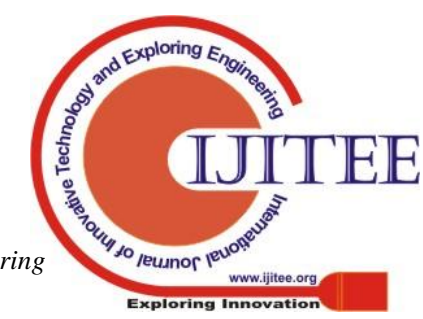




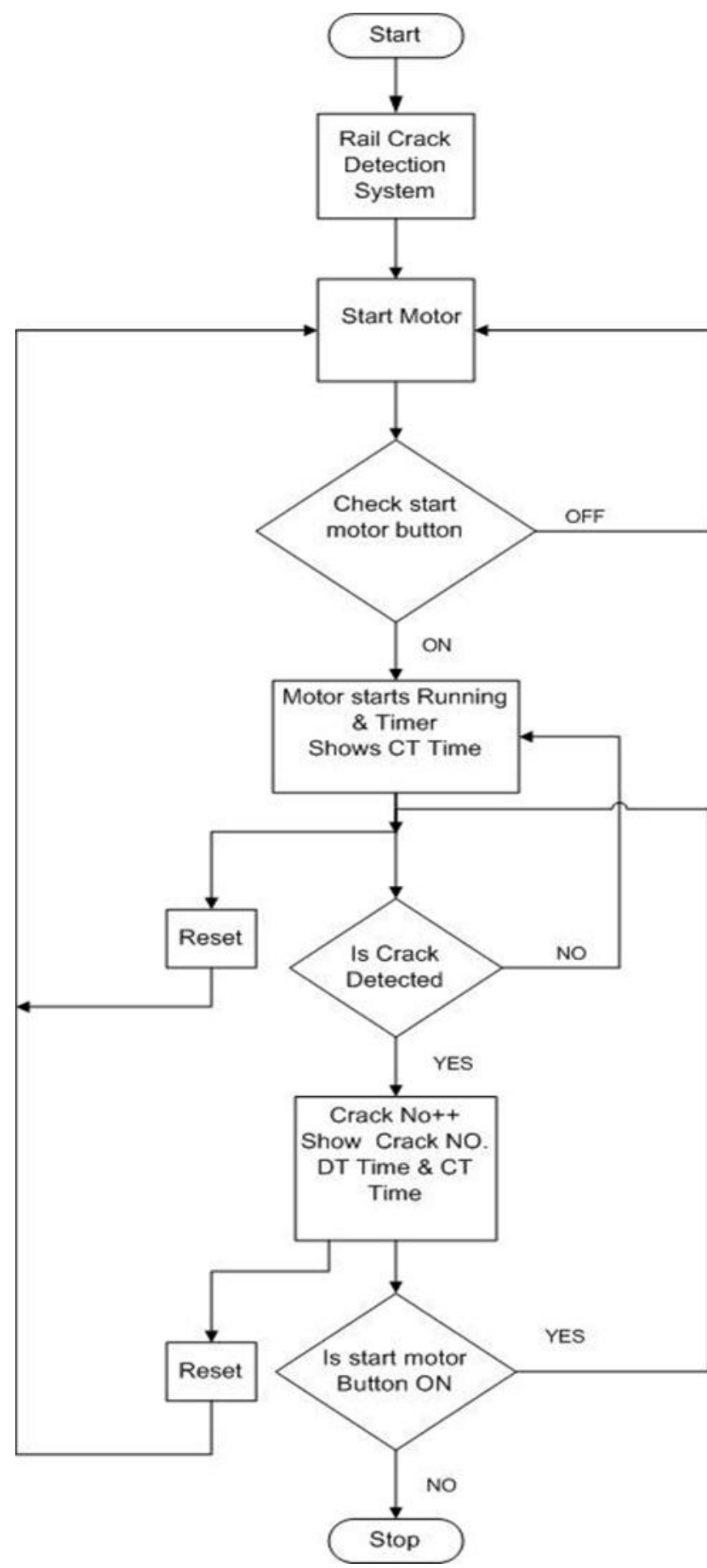

Fig:5 Flow diagram of crack detection system

\section{RESULTS}

The prototype of railway route crack detection system is shown by figure.6. In this model all the component that is sensor, microcontroller and LCD displaying unit are mounted on the movable robot. In order to detect the cracks on the railway track the robot moves on the track and sensor detects the crack if any and alert the user with the help of microcontroller. The microcontroller also controls the movement of the robot as required by the user. Table 2 shows the actual distance, measured distance and difference between actual and measured distance.

Table 2: Result
\begin{tabular}{|c|c|c|c|c|}
\hline $\begin{array}{c}\text { Gap } \\
\text { No }\end{array}$ & $\begin{array}{c}\text { Actual } \\
\text { Distance } \\
(\mathrm{cm})\end{array}$ & $\begin{array}{c}\text { Measured } \\
\text { Time } \\
(\mathrm{sec})\end{array}$ & $\begin{array}{c}\text { Measurcd } \\
\text { Distance } \\
(\mathrm{cm})\end{array}$ & $\begin{array}{c}\text { Difference } \\
\text { in Actual } \\
\& \\
\text { Measured } \\
\text { Distance }\end{array}$ \\
\hline 1 & 30 & 9 & 24.75 & 5.25 \\
\hline 2 & 50 & 16 & 44 & 6 \\
\hline 3 & 80 & 26 & 71.5 & 8.5 \\
\hline
\end{tabular}

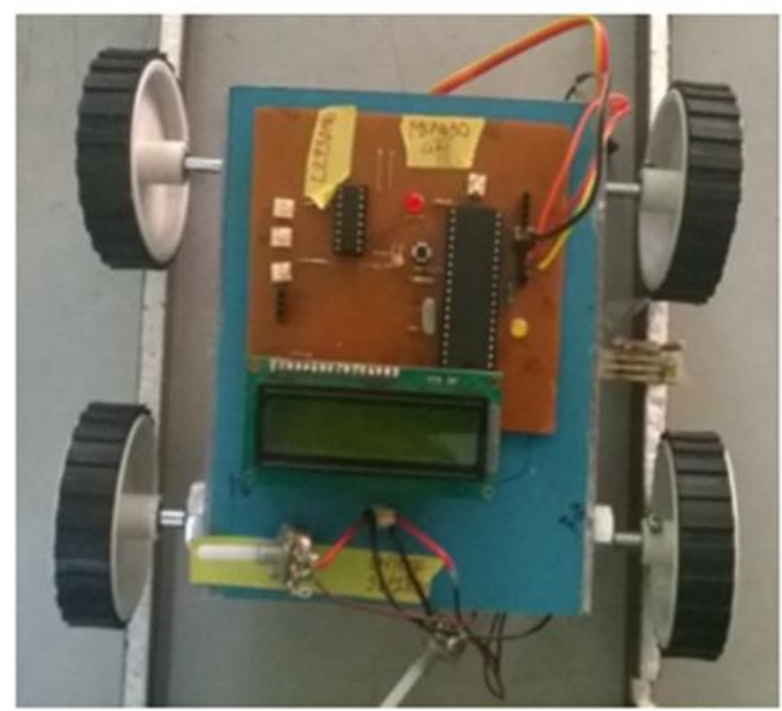

Fig. 6: Photograph of railway track crack detection system

\section{CONCLUSION}

The prototype of railway route crack detection system is successfully designed and is represented by fig.6. Large number of people travels in trains for going from one place to another due to its less reliability. In present era, the detection of cracks in the railway lines are done manually by the workers physically going to the railway track to do inspection. These inspections waste a lot of time and is very difficult task. Hence, the proposed method eliminates these efforts made by railway staff to search the cracks. From the proposed system the time spend on detecting the cracks of railway track is reduced by 60 percent.

\section{REFERENCES}

1. R. M. Lusby, J. Larsen, M. Ehrgott, and D. Ryan, "Railway track allocation: Models and methods," OR Spectrum. 2011.

2. International Union of Railways, "High speed lines in the world," World, 2011.

3. V. Profillidis, Railway Management and Engineering. 2017. 
4. A. W. Evans, "Rail safety and rail privatisation in Japan," Accid. Anal. Prev., 2010.

5. J. Chen, C. Roberts, and P. Weston, "Fault detection and diagnosis for railway track circuits using neuro-fuzzy systems," Control Eng. Pract., 2008.

6. X. Luan, J. Miao, L. Meng, F. Corman, and G. Lodewijks, "Integrated optimization on train scheduling and preventive maintenance time slots planning," Transp. Res. Part C Emerg. Technol., 2017.

7. A. Vanimireddy and D. A. Kumari, "Automatic Broken Track Detection Using LED-LDR Assembly," Int. J. Eng. Trends Technol., 2013.

8. A. G. Kostryzhev, C. L. Davis, and C. Roberts, "Detection of crack growth in rail steel using acoustic emission," Ironmak. Steelmak., 2012.

9. O. Ur-Rehman and N. Zivic, "Wireless communications," in Signals and Communication Technology, 2018.

10. J. Griffin, "DC motors," Electron. Power, 2010.

11. T. S. Ng, "Microcontroller," in Studies in Systems, Decision and Control, 2016.

12. N. Chadil, A. Russameesawang, and P. Keeratiwintakorn, "Real-time tracking management system using GPS, GPRS and Google Earth," in 5th International Conference on Electrical Engineering/Electronics, Computer, Telecommunications and Information Technology, ECTI-CON 2008, 2008 